\title{
Yield prediction and nitrogen recommendation in maize using normalized difference vegetation index
}

\author{
TB Karki \\ National Maize Research Program, Rampur, Chitwan, NARC, Nepal
}

\begin{abstract}
A study was carried out using three maize genotypes with three levels of nitrogen $(30 \mathrm{~kg}, 60 \mathrm{~kg}$ and $120 \mathrm{~kg}$ per hectare) during the summer season of 2010 and 2011with the aim of predicting maize (Zea mays L.) yield through the Normalized difference vegetation index (NDVI). The NDVI was recorded at different times throughout the growing season using a Greenseeker ${ }^{\mathrm{TM}}$ handheld sensor. Significant effect of genotypes and nutrient levels on the NDVI was observed at different growth stages of maize. There was positive correlation between the NDVI and grain yield. In the first season, the correlation coefficients were $0.90,0.92,0.76$ and 0.73 , respectively at $15,45,75$ and 110 days after seeding. In the second season, the correlation coefficients were $0.80,0.92,0.77$ and 0.75 respectively at $15,45,75$ and 110 days after seeding. The NDVI based $\mathrm{N}$ calculator showed that irrespective of genotypes, yield potentials under farmers' levels of nutrient management were almost half of the recommended doses of nitrogen. The amount of $\mathrm{N}$ to be top dressed decreased with increased crop duration. Grain yield varied significantly due to season, genotypes and nutrient levels. NDVI was affected due to season, stages of the crop (DAS), genotypes and nutrient levels. Interaction effects were significant for season $\mathrm{x}$ genotype, growth stage $\mathrm{x}$ genotype, growth stage $\mathrm{x}$ nutrient levels, genotype $\mathrm{x}$ nutrient levels and genotype $\mathrm{x}$ growth stage $\mathrm{x}$ nutrient levels. There was a strong positive correlation between NDVI and grain yields of hybrid maize at 15 and 45 DAS, but this correlation declined thereafter. This means that $\mathrm{N}$ top-dressed at or after 75 days of seed sowing will not increase grain yield as significantly as $\mathrm{N}$ applied earlier in the season. In contrast, topdressed $\mathrm{N}$ was producing significant effects on the open pollinated Rampur Composite even after 75 days of seed sowing. Further confirmation of the finding could be useful for top dressing $\mathrm{N}$ in the maize crop.
\end{abstract}

Key words : maize yield, prediction, normalized difference vegetation index

\section{Introduction}

Despite tremendous yield potential, maize productivity remains low in Nepal. This is a major challenge in national food security. Inefficient nutrient management plays a key role in poor maize yields. In Nepalese context, the normal farmers' practice is to apply all $\mathrm{N}$ fertilizer only once during the growing season, either as basal application before planting or topdressing approximately at 30 days after sowing. This type of application of nitrogenous fertilizer does not synchronize with crop $\mathrm{N}$ demand. Therefore, it is essential to develop appropriate $\mathrm{N}$ management technique to overcome environmental problems and low NUE. Normalized difference vegetative index (NDVI), which is widely used to estimate crop growth, has shown a good relationship with corn $\mathrm{N}$ status (Gitelson et al., 1996; Rambo et al., 2010) and grain yield (Inman et al., 2008). Thus, the NDVI has the potential to improve $\mathrm{N}$ use efficiency and ultimately, the productivity of maize. 


\section{Materials and methods}

This study was conducted at National Maize Research Program (NMRP), Rampur, Chitwan. The site is a continuous maize field under flooding irrigation and conventional tillage management. The site is located at the latitude of $27^{\circ} 39^{\prime} 10.8^{\prime \prime}$ north and the longitude of $84^{\circ} 20^{\prime} 52.55^{\prime \prime}$ east. Initial soil nutrient status of the experimental unit was $0.136 \% \mathrm{~N}, 47.32 \mathrm{~kg} / \mathrm{ha}$ of $\mathrm{P}$, and $82.24 \mathrm{~kg} / \mathrm{ha}$ of K. Soil texture of the site was sandy-loam. During the experimental period, the area received $103 \mathrm{~mm}$ rainfall in the first year and $99.4 \mathrm{~mm}$ rainfall in the second year.

A Complete Randomized Block (CRB) design was carried out with three maize genotypes and three rates of $\mathrm{N}$ as factors. Three maize genotypes were Rampur composite (a full season open pollinated variety requiring 108 days to mature), Rajkumar (a full season hybrid variety requiring 104 days to mature), and Shaktiman (a short season hybrid variety requiring 92 days to mature). Three rates of $\mathrm{N}$ were farmer's practice (30kg N/ha), half of the recommended dose $(60 \mathrm{~kg} \mathrm{~N} / \mathrm{ha})$, and the recommended dose $(120 \mathrm{~kg} \mathrm{~N} / \mathrm{ha})$. In this way, the experiment had a total of 9 treatments and each treatment was replicated thrice to account for spatial variability. Plot size for each treatment was of $5.4 \mathrm{x} 6 \mathrm{~m}^{2}$. Crop geometry was $60 \mathrm{~cm}$ between rows and $30 \mathrm{~cm}$ between plants within row. Seed sowing for the first crop was done on $2^{\text {nd }}$ June of 2010 and for the second crop was done on $29^{\text {th }}$ May of 2011.

An active hand-held sensor NTech's GreenSeeker ${ }^{\mathrm{TM}}$ was used for this study to determine NDVI using the equation below.

(1) NDVI $=($ Near Infrared Band Reflectance - Red $) /($ Near Infrared Band Reflectance + Red $)$

Sensor readings were recorded at 15, 45, 75 and 110 days after seed sowing. A sensor based nitrogen rate calculator developed by OSU, USDA-ARS and CIMMYT (www.soiltesting.okstate.edu) was used to predict the yield potentials and the amount of $\mathrm{N}$ to be top-dressed. Actual grain yield for each treatment was measured during the harvesting of the crop. Statistical analysis was performed by using GENSTATCTM Discovery version. When the treatment effect was significant at the alpha 0.05 level, the least significant difference (LSD) value was determined by using the means separation procedure.

\section{Results and discussion}

\section{Grain yield}

Grain yield was found to be significantly different between maize genotypes, nutrient levels and year/season. Furthermore, interaction between nutrient and genotypes was also significant (Table 1). Shaktiman with the highest level of nitrogen $(120 \mathrm{~kg} / \mathrm{ha})$ produced the highest grain yield followed by Rajkumar and Rampur composite at the same level of nitrogen. However, the yield variation at different nitrogen levels was significant for each tested genotype. Performance of hybrids was poor under the nitrogen level at farmers' practice in comparison to the open pollinated variety, Rampur composite. Performance of all three genotypes was better during the first summer than the second. This might be due uniform distribution of rainfall in the first season. Almaraz et al. (2009) reported that the corn response to $\mathrm{N}$ fertilizer was low under drought conditions during growing season. 
Table 1. Grain yields of maize as affected by genotypes and nutrient levels during summer 2010 and 2011 at Rampur, Chitwan, Nepal

\begin{tabular}{lcc}
\hline \multicolumn{1}{c}{ Treatments } & Grain Yield & Grain Yield \\
& $\mathbf{2 0 1 0}$ & $\mathbf{2 0 1 1}$ \\
\hline Rajkumar with farmer's practice (FP) of nutrient management & 2630.5 & 2506.2 \\
Rajkumar with 50 \% more of FP & 5402.9 & 5278.8 \\
Rajkumar with recommended doses of nutrients & 7898.8 & 7898.9 \\
Rampur composite with farmer's practice of fertilizer doses & 2993.8 & 2873.5 \\
Rampur composite 50 \% more of FP & 3096.8 & 3096.9 \\
Rampur composite with recommended doses of nutrients & 6294.3 & 6294.3 \\
Shaktiman with farmer's practice of nutrient management & 2819.0 & 2694.3 \\
Shaktiman 50 \% more of FP & 3207.9 & 3083.8 \\
Shaktiman with recommended doses of nutrients & 8274.6 & 8151.5 \\
Grand mean & 4930.0 & \\
CV,\% & 1.80 & \\
\hline
\end{tabular}

Significant at alpha 0.05 level of significance. Year ( LSD 52.7), Genotypes (LSD 59.2) Nutrients (LSD 59.2) Genotype x Nutrient (LSD 102.5)

\section{Normalized difference vegetation index (NDVI)}

NDVI data were significantly different between year/season, date of measurements, genotypes and nutrient levels. Significant interactions were recorded for season x genotype, duration x genotype, duration $\mathrm{x}$ nutrients, genotype $\mathrm{x}$ nutrients and genotype $\mathrm{x}$ nutrient $\mathrm{x}$ duration (Table 2, and Figure 1, 2, 3 and 4). Timing of $\mathrm{N}$ stress sensing with active canopy sensors was focused around the V10 V12 growth stages in maize in this study, and also as reported by (Solari et al., 2010). This timing may provide the best balance for attempting to accurately estimate maize $\mathrm{N}$ stress, provide adequate $\mathrm{N}$ fertilizer to growing maize plants when it is needed the most, and limit severity of lost yield potential due to $\mathrm{N}$ stress (Sawyer and Barker, 2012).

In 2010, this study showed a strong correlation between NDVI and grain yields of maize (Fig 3) at 45 and 15 DAS with correlation coefficients of 0.92 and 0.90 , respectively. At 75 and 110 DAS the correlation between NDVI and grain yield decreased drastically with correlation coefficients of 0.76 and 0.73 , respectively. Similarly, the correlation coefficients were $0.80,0.92,0.77$ and 0.75 respectively at 15, 45, 75 and 110 DAS in 2011. Liu and Wiatrak, (2011) also reported that V8 stage of maize corresponding to nearly 45 days after seeding correlated significantly with grain yield. 
Table 2. Sensor-based inputs and outputs table for both the year 2010 and 2011 Year 2010

\begin{tabular}{|c|c|c|c|c|c|c|c|c|c|}
\hline \multicolumn{6}{|c|}{ Inputs } & \multicolumn{4}{|c|}{ Outputs } \\
\hline Genotype & DAS & GDD & $\begin{array}{l}\text { NDVI } \\
\text {-FP }\end{array}$ & $\begin{array}{l}\text { NDVI- } \\
\text { N rich }\end{array}$ & $\begin{array}{l}\text { Maximu } \\
\text { m yield } \\
\text { (kg/ha) }\end{array}$ & RI & YPO-1 & YPO-2 & $\begin{array}{c}\mathrm{N} \\
\mathrm{kg} / \mathrm{ha}\end{array}$ \\
\hline Rajkumar & 45 & 673.5 & 0.231 & 0.589 & 8000 & 2 & 3203.4 & 6406.8 & 66.7 \\
\hline $\begin{array}{l}\text { Rampur } \\
\text { Composite }\end{array}$ & 45 & 673.5 & 0.231 & 0.567 & 8000 & 2 & 3203.4 & 6406.8 & 66.7 \\
\hline Shaktiman & 45 & 673.5 & 0.232 & 0.789 & 8000 & 2 & 3216 & 6432 & 67 \\
\hline Rajkumar & 75 & 1284.5 & 0.220 & 0.881 & 8000 & 2 & 2032.5 & 4065 & 42.3 \\
\hline $\begin{array}{l}\text { Rampur } \\
\text { Composite }\end{array}$ & 75 & 1284.5 & 0.264 & 0.794 & 8000 & 2 & 2225.6 & 4451.2 & 46.4 \\
\hline Shaktiman & 75 & 1284.5 & 0.212 & 0.599 & 8000 & 2 & 1999.2 & 3998.4 & 41.7 \\
\hline \multicolumn{10}{|l|}{ Year 2011} \\
\hline Genotype & DAS & GDD & $\begin{array}{l}\text { NDVI } \\
\text {-FP }\end{array}$ & $\begin{array}{l}\text { NDVI- } \\
\text { N rich }\end{array}$ & $\begin{array}{l}\text { Maximu } \\
\text { m yield } \\
\text { (kg/ha) }\end{array}$ & RI & YPO-1 & YPO-2 & $\begin{array}{c}\mathrm{N} \\
\mathrm{kg} / \mathrm{ha}\end{array}$ \\
\hline Rajkumar & 45 & 701.8 & 0.208 & 0.566 & 8000 & 2 & 2831.5 & 5663.1 & 59 \\
\hline $\begin{array}{l}\text { Rampur } \\
\text { Composite }\end{array}$ & 45 & 701.8 & 0.209 & 0.544 & 8000 & 2 & 2842.2 & 5684.5 & 59.2 \\
\hline Shaktiman & 45 & 701.8 & 0.209 & 0.777 & 8000 & 2 & 2842.2 & 5684.5 & 59.2 \\
\hline Rajkumar & 75 & 1047.9 & 0.197 & 0.788 & 8000 & 2 & 2124.6 & 4249.2 & 44.3 \\
\hline $\begin{array}{l}\text { Rampur } \\
\text { Composite }\end{array}$ & 75 & 1047.9 & 0.242 & 0.771 & 8000 & 2 & 2380.6 & 4761.3 & 49.6 \\
\hline Shaktiman & 75 & 1047.9 & 0.190 & 0.693 & 8000 & 2 & 2087.3 & 4174.8 & 43.5 \\
\hline
\end{tabular}

Note. $\mathrm{RI}=$ Response index; YPO-1 = Yield potential at farmers' practice; YPO-2= Yield potential at recommended dose

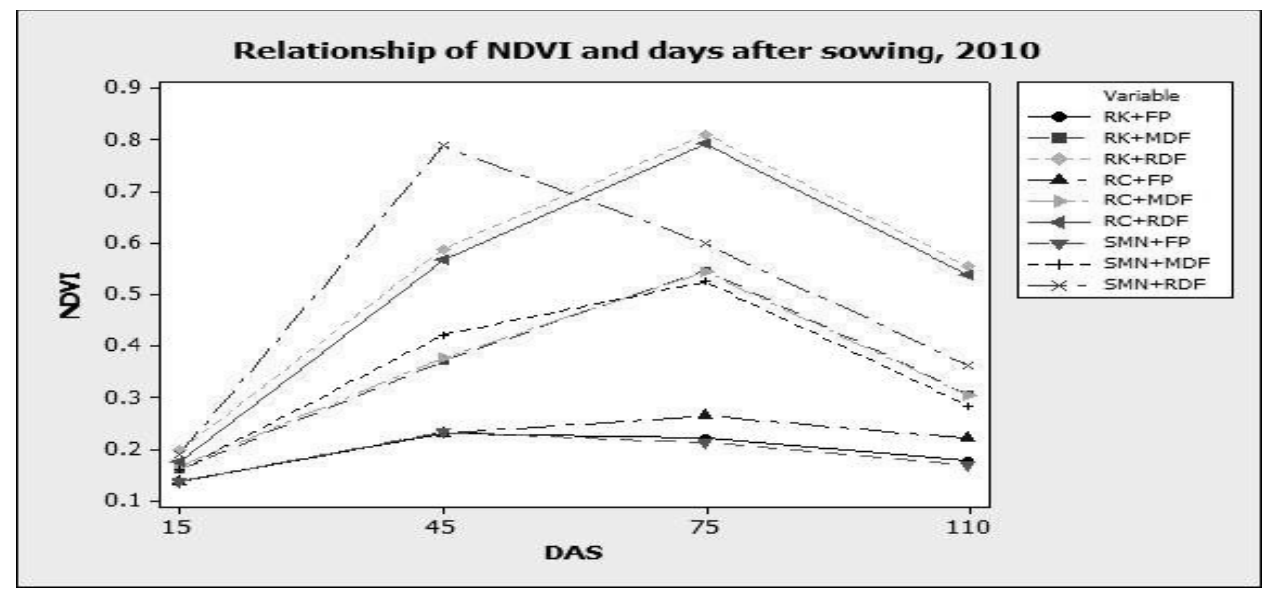

Figure 1. NDVI at different DAS as affected by maize genotypes and nutrient management during 
2010. $\mathrm{RK}+\mathrm{FP}=$ Rajkumar + Farmer's practice; $\mathrm{RK}+\mathrm{MDF}=$ Rajkumar + Medium Dose of Fertiliser; $\mathrm{RK}+\mathrm{RDF}=$ Rajkumar + Recommended Dose of Fertilizer; $\mathrm{RC}+\mathrm{FP}=$ Rampur Composite + Farmer's practice; $\mathrm{RC}+\mathrm{MDF}=$ Rampur Composite + Medium Dose of Fertiliser; $\mathrm{RC}+\mathrm{RDF}=$ Rampur Composite + Recommended Dose of Fertilizer; SMN+FP= Shaktiman + Farmer's Practice; $\mathrm{SMN}+\mathrm{MDF}+$ Shaktiman + Medium Doses of Fertilizer; SMN $+\mathrm{RDF}=$ Shaktiman + Recommended Doses of Fertilizer.

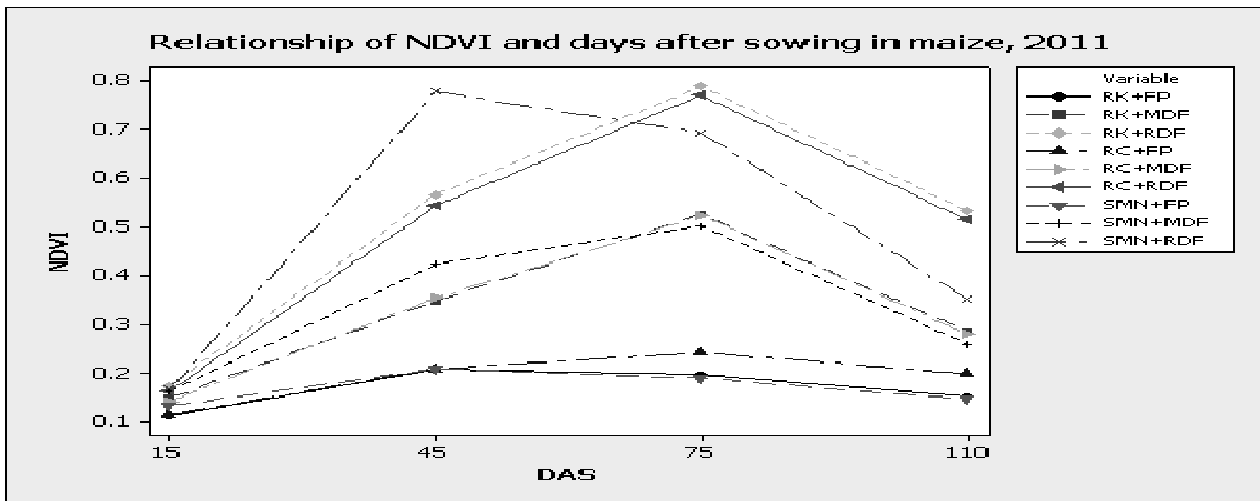

Figure 2. NDVI at different DAS as affected by maize genotypes and nutrient management during 2010.

Note. $\mathrm{RK}+\mathrm{FP}=$ Rajkumar + Farmer's practice; $\mathrm{RK}+\mathrm{MDF}=$ Rajkumar + Medium Dose of Fertiliser; $\mathrm{RK}+\mathrm{RDF}=$ Rajkumar + Recommended Dose of Fertilizer; $\mathrm{RC}+\mathrm{FP}=$ Rampur Composite + Farmer's practice; $\mathrm{RC}+\mathrm{MDF}=$ Rampur Composite + Medium Dose of Fertiliser; $\mathrm{RC}+\mathrm{RDF}=$ Rampur Composite + Recommended Dose of Fertilizer; $\mathrm{SMN}+\mathrm{FP}=$ Shaktiman + Farmer's Practice; $\mathrm{SMN}+\mathrm{MDF}+$ Shaktiman + Medium Doses of Fertilizer; SMN $+\mathrm{RDF}=$ Shaktiman + Recommended Doses of Fertilizer.

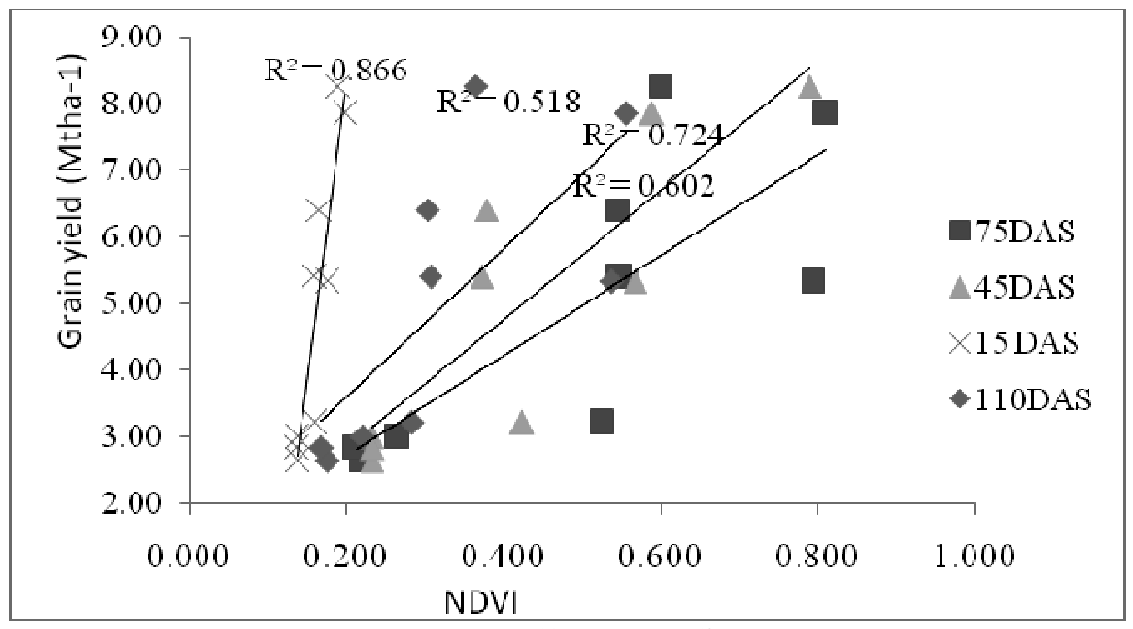

Figure 3. Grain yield vs. NDVI at different DAS, 2010 


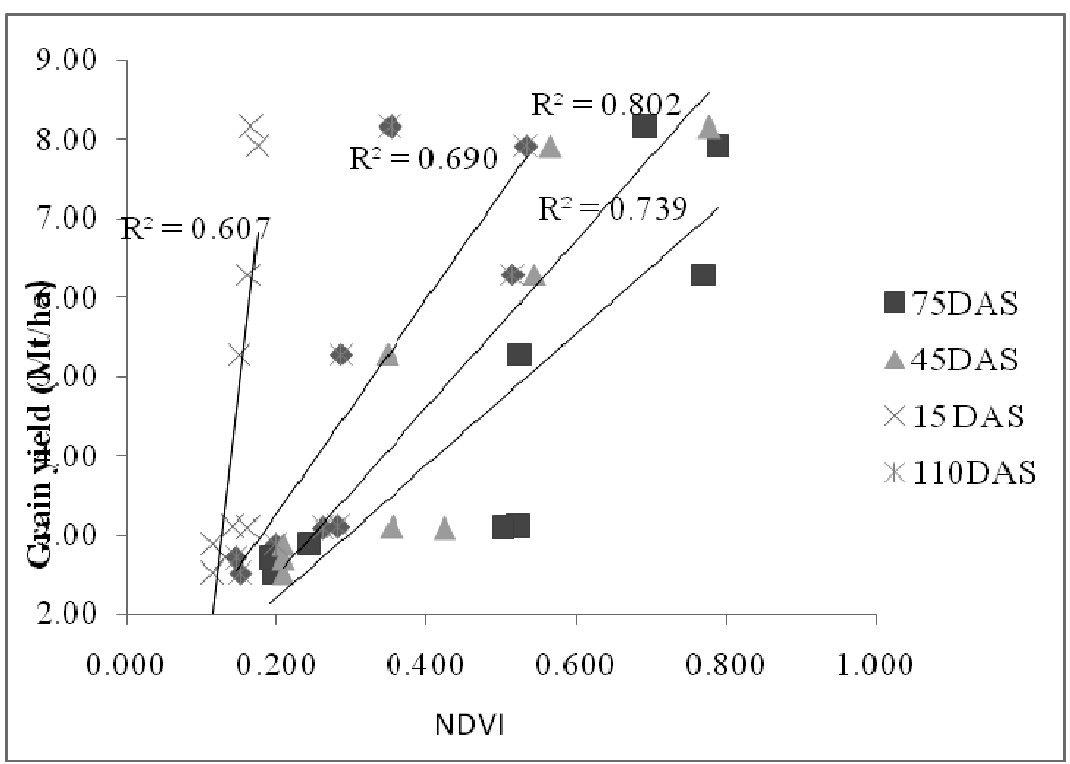

Figure 4. Grain yield vs NDVI at different DAS, 2011

\section{Predicting the grain yield and $\mathbf{N}$ status in maize}

NDVI-based N calculator revealed that Shaktiman had a yield potential of $3216 \mathrm{~kg} / \mathrm{ha}$ under FP and $6432 \mathrm{~kg} / \mathrm{ha}$ in RDF if an estimated $67 \mathrm{~kg} \mathrm{~N} / \mathrm{ha}$ were top-dressed at $45 \mathrm{DAS}$. In the contrary, if $\mathrm{N}$ was not applied until 75 DAS, hybrid yield potentials decreased significantly whereas the open pollinated genotype (Rampur Composite) was not severely affected by late $\mathrm{N}$ topdressing (Table 2). Early maturing genotypes generally enter their reproductive stage by 75 DAS and thus have a reduced response to $\mathrm{N}$ and low $\mathrm{N}$ use efficiency after this stage. There was a possibility of increasing yield potential of Rampur Composite through additional $\mathrm{N}$ topdressing at or before 75 days of seed sowing. However, irrespective of genotype and nutrient levels the Relative Index (RI) was almost same for each date of sampling and season.

\section{Acknowledgements}

The author is highly indebted to NARC and NMRP, Rampur and CIMMYT, Nepal for all sorts of support rendered to carry out the experiment. I am also thankful to Mr. John Laborde, graduate student from University of Nebraska for his help in preparing this manuscript. 


\section{References}

Almaraz JJ, F Mabood, X Zhou, I Strachan, B Ma, DL Smith. 2009. Performance of agricultural systems under contrasting growing season conditions in south-western Quebec. J. Agron. and Crop Sci. 195.319-327.

Gitelson AA, YJ Kaufman and MN Merzlyak. 1996. Use of a green channel in remote sensing of global vegetation from EOS-MODIS. Remote Sens. Environ. 58.289-298.

Inman D, R Khosla, RM Reich and DG Westfall. 2008. Normalized difference vegetation index and soil color-based management zones in irrigated maize. Agron. J. 100.60-66.

Liu K and P Wiatrak. 2011. Corn production and plant characteristics response to $\mathrm{N}$ fertilization management in dry-land conventional tillage system. International Journal of Plant Production 5(4).1735-1738

Rambo L, BL Ma, YC Xiong and PRF da Silvia 2010. Leaf and canopy optical characteristics as crop-N-status indicators for field nitrogen management in corn. J. Plant Nutr. Soil Sci. $173.434-443$

Sawyer JE and DW Barker. 2012. Quantifying corn N deficiency with active canopy sensors. Proc. of the 2012 Wisconsin Crop Management Conference, Vol. 51.

Solari F and JF Shanahan, RB Ferguson and VI Adamchuk. 2010. An active sensor algorithm for corn nitrogen recommendations based on a chlorophyll meter algorithm. Agron. J. 102.1090-1098. 